\title{
Can pre-diagnostic serum levels of sodium and potassium predict prostate cancer survival?
}

\author{
Arunangshu Ghoshal ${ }^{1,8^{*}}$ (D), Hans Garmo ${ }^{1,2}$, Niklas Hammar ${ }^{3,4}$, Ingmar Jungner ${ }^{5}$, Håkan Malmström,
} Göran Walldius ${ }^{7}$ and Mieke Van Hemelrijck ${ }^{1,3}$

\begin{abstract}
There is evidence that derangement in serum electrolytes like sodium and potassium is associated with increased morbidity and mortality among hospitalized critically ill patients, but their role in the context of cancer survival remains poorly understood. We sought to investigate the association of pre-diagnostic serum sodium and potassium with risk of overall, cancer-specific, and cardiovascular (CV) death among 11,492 men diagnosed with prostate cancer (PCa) from the Swedish AMORIS study. Multivariable Cox proportional hazards regression was used to assess the risk of death by clinical categories of pre-diagnostic serum sodium and potassium. During a mean follow-up of 5.7 years, 1649 men died of PCa. Serum levels of sodium were not indicative of PCa-specific or CV death. A weak positive association was found between pre-diagnostic higher serum potassium (> $5 \mathrm{mEg} / \mathrm{L}$ ) and overall death [HR: 1.26 (95\% Cl: 1.01-1.59)] as compared to low/normal levels of clinical cut-offs. The current study did not find strong evidence for a role of electrolytes in PCa mortality. To further disentangle the potential role of electrolytes in cancer development, future studies should use repeated measurement of serum electrolytes.

This research project was reviewed and approved by the Stockholm Ethical Committee (Dnr 2010/1:7).
\end{abstract}

Keywords: AMORIS cohort, Prospective study, Prostate cancer, Serum electrolytes, Survival analysis

\section{Introduction}

Fluid and electrolyte imbalances are thought to be associated with increased morbidity and mortality among hospitalized critically ill (cancer) patients [1,2]. They have also been extensively studied in relation to cardiovascular-specific death [3]. Even though serum electrolytes like sodium $(\mathrm{Na})$ and potassium $(\mathrm{K})$ are routinely measured in clinical practice, most studies to date are based on hospital data with these measurements taken at time of diagnosis or treatment initiation [4]. However, the effects of electrolyte imbalances may influence health outcomes over a much longer time. In a study by Verma A, et al. [5] using the National Health and Nutrition Examination survey (NHANES) data

\footnotetext{
* Correspondence: arung@kcl.ac.uk

${ }^{1}$ Translational Oncology \& Urology Research, Kings's College London, School of Cancer and Pharmaceutical Sciences, 3rd Floor, Bermondsey Wing, Guy's Hospital, London SE1 9RT, UK

${ }^{8}$ Department of Palliative Medicine, Tata Memorial Hospital, Mumbai 40012, India

Full list of author information is available at the end of the article
}

(1999-2010), a higher serum anion gap was associated with increase in cancer mortality. A recent systematic review also highlighted the need to understand the potential role of these electrolytes in the context of carcinogenesis [6].

Prostate cancer $(\mathrm{PCa})$ is the most common non-cutaneous cancer in men. Although $\mathrm{PCa}$ can be a slow-growing cancer, it is the second most common cause of cancer death in males globally [7]. The most important and established indicators of prognosis for PCa include Gleason grade, extent of tumour volume, and presence of capsular penetration or margin positivity at time of prostatectomy [8]. To our knowledge, there are no studies yet evaluating the effect of pre-diagnostic electrolyte imbalances on PCa mortality.

Hence, we sought to investigate the association between pre-diagnostic serum $\mathrm{Na}$ and $\mathrm{K}$ and overall, cancer-specific, and cardiovascular death among 11,492 men with $\mathrm{PCa}$ in a prospective cohort study with up to 25 years of follow-up. 


\section{Methods}

\section{Study population and data collection}

The Swedish Apolipoprotein-related MOrtality RISk database (AMORIS) includes blood samples from 812,073 Swedish men and women, ranging in age from $<20$ to $80+$ years undergoing occupational health screening or primary care. The cohort is based on a linkage between data from laboratory examinations performed in the Central Automation Laboratory (CALAB) in Sweden and information recorded in Swedish National Registers using a 10-digit personal identifier number, which is unique to every Swedish resident. Individuals recruited were primarily from the greater Stockholm area, who were either healthy and having laboratory testing as part of a general checkup or outpatients referred for laboratory testing. None of the participants were inpatients at the time of sampling. In the AMORIS cohort, the CALAB database was linked to several Swedish national registries such as the Swedish National Cancer Register, the Hospital Discharge Register, the Cause of Death Register, the consecutive Swedish Censuses during 1970-1990, and the National Register of Emigration using the Swedish 10-digit personal identity number $[9,10]$. Detailed description of the AMORIS cohort can be found elsewhere [11].

For this study, we specifically focused on the linkage between the AMORIS database and the National Prostate Cancer Register (NPCR), which has been nationwide since 1998 [12]. NPCR was developed to provide data for quality assurance and includes $98 \%$ of all newly diagnosed PCa cases registered in the Swedish National Cancer Register [12] to which reporting is mandated. From the NPCR, we extracted information on date of diagnosis, age at diagnosis, TNM stage [13], Gleason score, serum concentration of PSA at time of diagnosis, and primary treatment given or planned up to 6 months after date of diagnosis. Information on educational level was retrieved from the Population and Housing Census for 1970-1990. Using information from the National Patient Register, we calculated the Charlson Comorbidity Index which includes 19 diseases, with each disease category assigned a weight. The sum of an individual's weights was used to create a score, resulting in four comorbidity levels ranging from no comorbidity to severe comorbidity $(0,1,2$, and $\geq 3)[14]$. AMORIS is a large prospective cohort with information on serum biomarkers, cancer diagnosis, co-morbidities, vital status, socioeconomic status, and emigration. This study complied with the Declaration of Helsinki and was approved by the Ethics Review Board of the Karolinska Institute [11].

We included all men aged 20+ years diagnosed with no previous diagnosis of any cancer, and measurements of serum $\mathrm{Na}$ and $\mathrm{K}$ available from the same health examination on average 13 years [interval time (range: 0.01-25.9 years)] prior to the diagnosis of $\mathrm{PCa}$ $(n=11,492)$. $\mathrm{Na}$ and $\mathrm{K}$ were assessed based on their standard clinical cut-offs in serum (Na: 136-145 mEq/ L, K: $3.5-5 \mathrm{mEq} / \mathrm{L}$ ) [15]. Follow-up time was defined as time from $\mathrm{PCa}$ diagnosis until date of cancer death, date of death, emigration, or end of study (31st December 2011), whichever came first. The primary outcome investigated in this study was death from prostate cancer (International Classification of Diseases, Revision 7 (1955) code 177), as registered in the National Cause of Death Register [16].

We estimated risk of death with multivariate Cox proportional hazards regression in relation to serum levels of $\mathrm{Na}$ and $\mathrm{K}$, whilst adjusting for interval time (i.e. time between measurement and diagnosis), and the following information from AMORIS: age, educational level (low, intermediate, high), Charlson Comorbidity Index, PCa severity (defined by PCa risk categories $^{1}$ and clinicopathological characteristics (i.e., PSA, Gleason score, and TNM staging) in the updated AMORIS cohort [17]): low, intermediate, and high), and serum creatinine $(\mu \mathrm{mol} / \mathrm{L})$ (continuous). CCI was calculated using information from the National Patient Register and consists of 18 groups of diseases with a specific weight assigned to each disease category, summed to obtain an overall score, resulting in four comorbidity levels $(0,1,2$, and $\geq 3$ ) [18]. We also created a combined electrolyte score by adding the clinical cut-off variables for $\mathrm{Na}$ and $\mathrm{K}$. The score ranged from 0 to 4 (0,1: low levels of $\mathrm{Na}$ and/or K, 2: normal levels of $\mathrm{Na}$ and/or $\mathrm{K}, 3,4$ : high levels of $\mathrm{Na}$ and/or $\mathrm{K}$ ). Additionally, we performed stratified analyses by quartiles of age at baseline (36, 64,69 , and 75 years) and interval time $(0.01,9,14$, and 18 years), and sensitivity analyses excluding $\mathrm{PCa}$ death $<3$ years and $<5$ years after $\mathrm{PCa}$ diagnosis.

All analyses were conducted with Statistical Analysis Systems (SAS) release 9.4 [19]. The assumption of proportionality was checked using the methods of Lin, Wei, and Ying [20]. This study complied with the Declaration of Helsinki and was approved by the Ethics board of the Karolinska Institute.

\section{Results}

During a mean follow-up time of 5.7 years [range: $(0.01-$ 24.5 years)], 1649 men died of PCa and 485 of cardiovascular diseases out of 3995 deaths. Baseline characteristics of the study participants are shown in Table 1 . Most subjects had value of $\mathrm{Na}$ and $\mathrm{K}$ in the middle categories of $\mathrm{Na}$ and $\mathrm{K}$.

When using the clinical cut-off of serum $\mathrm{Na}$ and $\mathrm{K}$ as well as a combined electrolyte score, we only observed a weak positive association with all-cause mortality for 
Table 1 Descriptive statistics of the study population (men diagnosed with Prostate Cancer in AMORIS) $(n=11,492)$

\begin{tabular}{|c|c|c|c|c|c|c|}
\hline & \multicolumn{3}{|c|}{ Sodium $(\mathrm{mEq} / \mathrm{L})$ Mean = $140.71(\mathrm{SD}=2.92)$} & \multicolumn{3}{|c|}{ Potassium (mEq/L) Mean = $4.26(\mathrm{SD}=0.33)$} \\
\hline & $\begin{array}{l}<136 \\
(n=255)\end{array}$ & $\begin{array}{l}136-145 \\
(n=10,584)\end{array}$ & $\begin{array}{l}>145 \\
(n=653)\end{array}$ & $\begin{array}{l}<3.5 \\
(n=47)\end{array}$ & $\begin{array}{l}3.5-5 \\
(n=11,268)\end{array}$ & $\begin{array}{l}>5 \\
(n=177)\end{array}$ \\
\hline Mean age (yrs.) (SD) & $69.7(8.3)$ & $69.5(8.1)$ & $69.4(8.0)$ & $70.4(8.5)$ & $69.5(8.1)$ & 70.7 (8.6) \\
\hline \multicolumn{7}{|c|}{ Socio-economic status (\%) } \\
\hline White collar & $152(59.61)$ & $7145(67.51)$ & $455(69.68)$ & $29(61.7)$ & $7609(67.53)$ & $114(64.41)$ \\
\hline Blue collar & $85(33.33)$ & $2903(27.43)$ & $169(25.88)$ & $17(36.17)$ & $3095(27.47)$ & $45(25.42)$ \\
\hline Unemployed/missing & $18(7.06)$ & $536(5.06)$ & $29(4.44)$ & $1(2.13)$ & $564(5.01)$ & $18(10.17)$ \\
\hline \multicolumn{7}{|l|}{ Education (\%) } \\
\hline Low & $78(30.59)$ & $2782(26.28)$ & $178(27.26)$ & $18(38.29)$ & $2979(26.44)$ & $41(23.16)$ \\
\hline Middle & $102(0.4)$ & $4323(40.84)$ & $257(39.36)$ & $17(36.17)$ & $4584(40.68)$ & $81(45.76)$ \\
\hline High & $152(59.61)$ & $3137(29.64)$ & $202(30.93)$ & $11(23.4)$ & 3351 (29.74) & $46(25.99)$ \\
\hline Missing & $6(2.35)$ & $342(3.23)$ & $16(2.45)$ & $1(2.13)$ & $354(3.14)$ & $9(5.08)$ \\
\hline \multicolumn{7}{|c|}{ Charslon Co-morbidity Index (\%) } \\
\hline 0 & $160(62.74)$ & $6947(65.64)$ & $435(66.62)$ & $28(59.57)$ & $7411(65.77)$ & $103(58.19)$ \\
\hline 1 & $37(14.51)$ & $1464(13.83)$ & $84(12.86)$ & $10(21.28)$ & $1544(13.7)$ & $31(17.51)$ \\
\hline 2 & $33(12.94)$ & $1325(12.52)$ & $84(12.86)$ & $7(14.89)$ & $1414(12.55)$ & $21(11.86)$ \\
\hline $3+$ & $25(9.80)$ & $848(8.01)$ & $50(7.66)$ & $2(4.26)$ & 899 (7.98) & $22(12.43)$ \\
\hline \multicolumn{7}{|c|}{ Body mass index $\left(\mathrm{kg} / \mathrm{m}^{2}\right)(\%)$} \\
\hline$<18.5$ & - & $9(0.08)$ & - & - & $9(0.08)$ & - \\
\hline $18.5-24.99$ & $28(10.98)$ & $919(8.68)$ & $62(9.49)$ & $4(8.51)$ & 989 (8.78) & $16(9.04)$ \\
\hline $25-29.99$ & $20(7.84)$ & $932(8.80)$ & $55(8.42)$ & $5(10.64)$ & $991(8.79)$ & $11(6.21)$ \\
\hline$>=30$ & $5(1.96)$ & $195(1.84)$ & $11(1.68)$ & $1(2.13)$ & $208(1.84)$ & $2(1.13)$ \\
\hline Missing & $202(79.21)$ & $8529(80.58)$ & $525(80.39)$ & $37(78.72)$ & $9071(80.5)$ & $148(83.61)$ \\
\hline \multicolumn{7}{|l|}{ Creatinine (micromol/L) } \\
\hline Mean (SD) & $89.39(16.47)$ & $89.80(18.95)$ & $91.66(12.47)$ & $90.89(15.29)$ & $89.63(13.49)$ & $106.98(103.33)$ \\
\hline Missing (\%) & $1(0.39)$ & $59(0.56)$ & $2(0.31)$ & 0 & $59(0.52)$ & $3(1.69)$ \\
\hline \multicolumn{7}{|l|}{ Interval time (years) } \\
\hline Mean (SD) & $13.3(6.6)$ & $13.2(6.3)$ & $14.3(5.9)$ & $11.3(7.2)$ & $13.3(6.3)$ & $12.1(6.6)$ \\
\hline \multicolumn{7}{|l|}{ Cancer severity (\%) } \\
\hline Low risk & $49(19.21)$ & 2337 (22.08) & $157(24.04)$ & $12(25.53)$ & $2493(22.12)$ & $38(21.47)$ \\
\hline Intermediate risk & $50(19.61)$ & $2299(21.72)$ & $139(21.29)$ & $9(19.15)$ & $2445(21.69)$ & $34(19.21)$ \\
\hline High risk & $46(18.04)$ & $1917(18.11)$ & 109 (16.69) & $7(14.89)$ & $2035(18.06)$ & $30(16.95)$ \\
\hline Regionally metastatic & $14(5.49)$ & $511(4.83)$ & $38(5.82)$ & - & $559(4.96)$ & $4(2.26)$ \\
\hline Distant metastases & $20(7.84)$ & $814(7.69)$ & $56(8.57)$ & $3(6.38)$ & $870(7.72)$ & $17(9.6)$ \\
\hline Missing & $76(29.80)$ & $2706(25.57)$ & $154(23.58)$ & $16(34.04)$ & $2866(25.43)$ & $54(30.51)$ \\
\hline
\end{tabular}

higher serum levels of K [HR: 1.26 (95\% CI: $1.01-$ 1.59)], as compared to low levels according to the medical cut-off (Table 2). No meaningful associations were observed between serum $\mathrm{Na}$ levels or combined electrolyte score and PCa-specific mortality, Overall mortality and Cardiovascular mortality. Additional adjustments for creatinine levels, time between measurement and PCa diagnosis, and PCa severity weakened this association: HR 1.11 (95\% CI: 0.79-1.55). Stratified analyses by age and interval time and sensitivity analyses excluding rapidly fatal PCa did not alter the above-described associations (results not shown).

\section{Discussion}

Pre-diagnostic Na levels were not associated with $\mathrm{PCa}$ death. Although higher serum potassium was associated with an increased risk of all-cause mortality, the associations were weak without any clear trend. Data from in-vitro, in-vivo models and ecological studies suggest that serum $\mathrm{Na} / \mathrm{K}$ represent a potentially modifiable exposure 


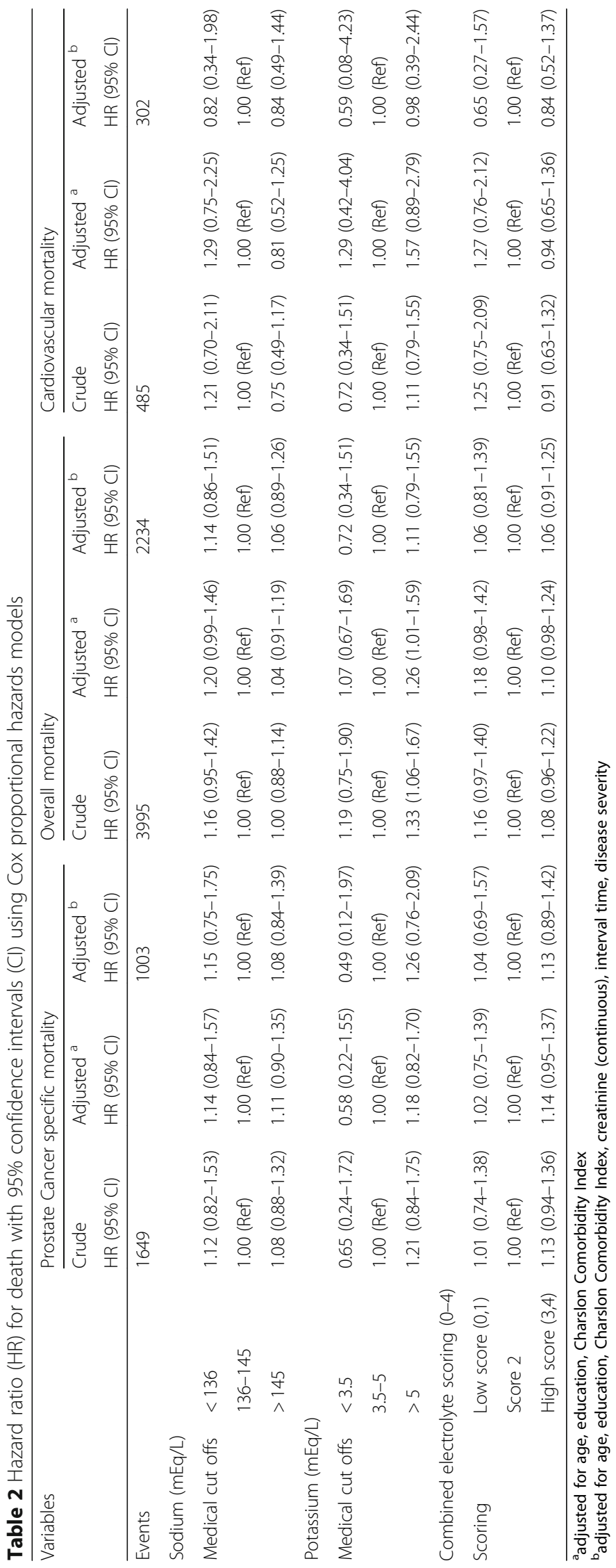


that could affect PCa mortality [21]. Even in clinical studies, electrolyte disorders are commonly encountered in cancer patients, and pre-treatment hyponatremia has been associated with higher mortality in localized and metastatic renal cell carcinoma [22], malignant pleural mesothelioma [23], and small-cell lung cancer [24]. While findings reported here do not support this hypothesis, they do illustrate potential pitfalls with studies of serum levels of $\mathrm{Na} / \mathrm{K}$ and $\mathrm{PCa}$ outcomes.

Results from these studies should be carefully interpreted as there are several concerns related to timing of serum sample collection and relevant exposure thresholds. For instance, if $\mathrm{Na} / \mathrm{K}$ status was measured postdiagnosis or post-treatment, possibility of reverse causality and modification by treatment exist, but we did not observe an association with rapidly fatal PCa. However, even though we grouped $\mathrm{Na} / \mathrm{K}$ status into clinically relevant categories, we did not have data to examine seasonally-adjusted $\mathrm{Na} / \mathrm{K}$ status or a potential dose effect as to verify the assumption of a linear relationship between serum $\mathrm{Na} / \mathrm{K}$ and prognosis [25-28]. Interestingly, $\mathrm{Na} / \mathrm{K}$ exposure at $\mathrm{PCa}$ tissue microenvironment may not be a surrogate of commonly measured serum levels [29]. The lack of an association in our study might also be due to limited information on additional serum electrolytes like Magnesium $(\mathrm{Mg})$ or single observations over a long interval time - however stratification by interval time did not alter our observations. To our knowledge no other study has yet investigated the role of electrolytes in $\mathrm{PCa}$ progression. Hence, further research is required to disentangle their role- pre-clinical studies on $\mathrm{PCa}$, observational studies with repeated measurements, testing of causal relationship through linear as well as polynomial models, adding additional electrolytes like $\mathrm{Mg}$, investigating the seasonal/ dietary factors involved in regulation serum electrolytes, etc.

To date, this is the largest prospective study assessing pre-diagnostic serum electrolytes in relation to $\mathrm{PCa}$-specific death. There was limited information for potential covariates such as renal and endocrine functions or additional serum electrolytes. However, all models were adjusted for CCI. It is a limitation of our study that we did not have repeated measurements of $\mathrm{Na}$ and $\mathrm{K}$, as this could have provided more information on the natural history of PCa. Another limitation is that we did not account for PCa treatment when studying mortality, however by considering disease severity at time of diagnosis we have taken into account the best proxy possible.

\section{Conclusion}

We did not find any marked association between commonly measured serum electrolytes prior to diagnosis and risk of death from $\mathrm{PCa}$, cardiovascular disease, or all-cause mortality. Future studies should investigate temporality of these associations using a modelling approach based on repeated measurement of electrolytes to provide more insight into these possible links.

\section{Endnotes}

${ }^{1}$ risk categories were defined in accordance with an adapted version of National Comprehensive Cancer Network as low risk (T1-2, Gleason score 2-6 and PSA $<10 \mathrm{ng} / \mathrm{mL})$, intermediate risk (T1-2, Gleason score 7 and/or PSA 10 to $<20 \mathrm{ng} / \mathrm{mL}$ ), high risk (T3 and/or Gleason score 8-10 and/or PSA 20 to $<50$ $\mathrm{ng} / \mathrm{mL}$ ), and regionally metastatic tumors ( $\mathrm{T} 4$ and/or $\mathrm{N} 1$ and/or PSA $50-<100 \mathrm{ng} / \mathrm{mL}$ in the absence of distant metastases (M0 or MX)) and distant metastatic tumors (M1 and/or PSA > $100 \mathrm{ng} / \mathrm{mL}$ ) [12]

\section{Abbreviations \\ AMORIS: Apolipoprotein-related MOrtality RISk; CALAB: Central Automation Laboratory; CCl: Charlson Comorbidity Index; Cl: Confidence interval; HR: Hazard ratio; K: potassium; mEq/L: milliequivalents per litre; Mg: Magnesium; Na: sodium; NHANES: National Health and Nutrition Examination survey; PCa: prostate cancer; RCS: restricted cubic splines; SAS: Statistical Analysis System; SD: Standard deviation; $\mu \mathrm{mol} / \mathrm{L}$ : micromole per litre}

\section{Acknowledgements}

The Swedish Cancer Society; Gunnar and Ingmar Jungner Foundation for Laboratory Medicine, Stockholm, Sweden; and the National Institute for Health Research (NIHR) Biomedical Research Centre based at Guy's and St Thomas' NHS Foundation Trust and King's College London.

\section{Funding}

The research was funded/supported by the Swedish Cancer Society; grants from the Gunnar and Ingmar Jungner Foundation for Laboratory Medicine, Stockholm, Sweden; and the National Institute for Health Research (NIHR) Biomedical Research Centre based at Guy's and St Thomas' NHS Foundation Trust and King's College London. The views expressed are those of the author(s) and not necessarily those of the Cancerfonden, NHS, the NIHR or the Department of Health.

Availability of data and materials

All data generated or analysed during this study are included in this published article [and its supplementary information files] [11].

\section{Authors' contributions}

AG and HG: project development, data analysis, manuscript writing. $\mathrm{NH}, \mathrm{IJ}$, HM, and GW: Data collection and manuscript editing. MVH: Project development and manuscript editing. All authors read and approved the final manuscript.

\section{Ethics approval and consent to participate}

All procedures performed in studies involving human participants were in accordance with the ethical standards of the institutional and/or national research committee and with the 1964 Helsinki declaration and its later amendments or comparable ethical standards.

Informed consent was obtained from all individual participants included in the study.

Consent for publication

Not applicable.

\section{Competing interests}

The authors declare that they have no competing interest. M Van Hemelrijck is an Editorial Board Member of BMC Cancer. 


\section{Publisher's Note}

Springer Nature remains neutral with regard to jurisdictional claims in published maps and institutional affiliations.

\section{Author details}

'Translational Oncology \& Urology Research, Kings's College London, School of Cancer and Pharmaceutical Sciences, 3rd Floor, Bermondsey Wing, Guy's Hospital, London SE1 9RT, UK. ${ }^{2}$ Regional Cancer Centre, Uppsala University, Box 25675105 Uppsala, Sweden. ${ }^{3}$ Unit of Epidemiology, Institute of Environmental Medicine, Karolinska Institutet, SE-171 77 Stockholm, Sweden. ${ }^{4}$ AstraZeneca R\&D, 43150 Mölndal, Sweden. ${ }^{5}$ Department of Medicine, Clinical Epidemiological Unit, Karolinska Institutet and CALAB Research, SE-171 77 Stockholm, Sweden. ${ }^{6}$ Biostatistics, Research \& Development, Swedish Orphan Biovitrum AB, SE-112 76 Stockholm, Sweden. ${ }^{7}$ Unit of Cardiovascular Epidemiology, Institute of Environmental Medicine, Karolinska Institutet, SE-171 77 Stockholm, Sweden. ${ }^{8}$ Department of Palliative Medicine, Tata Memorial Hospital, Mumbai 40012, India.

\section{Received: 13 February 2018 Accepted: 15 November 2018}

\section{Published online: 26 November 2018}

\section{References}

1. Lee JW. Fluid and electrolyte disturbances in critically ill patients. Electrolyte Blood Press. Korean Society of Electrolyte Metabolism. 2010; 8:72-81 [cited 2017 Aug 1] Available from: http://www.ncbi.nIm.nih.gov/ pubmed/21468200.

2. Osterlind K. Factors confounding evaluation of treatment effect in lung cancer. Lung Cancer. 1994;10(Suppl 1):S97-103 [cited 2017 Aug 8] Available from: http://inkinghub.elsevier.com/retrieve/pii/0169500294916721.

3. Geleijnse JM, Witteman JCM, Stijnen T, Kloos MW, Hofman A, Grobbee DE. Sodium and potassium intake and risk of cardiovascular events and all-cause mortality: The Rotterdam Study. Eur J Epidemiol. 2007; 22:763-70 [cited 2017 Nov 12] Available from: http://www.ncbi.nlm. nih.gov/pubmed/17902026

4. Bowman BT. Onco-Nephrology Highlights | Electrolyte disorders associated with cancer. J Onco-Nephrology. 2017;1:30-5 [cited 2017 Aug 1] Available from: https://journals.sagepub.com/doi/10.5301/jo-n.5000004.

5. Verma A, Qayyum R. Anion gap and cancer mortality: Insight from NHANES database. J Clin Oncol 2017;35:e13068-e13068. Available from: http:// ascopubs.org/doi/abs/10.1200/JCO.2017.35.15_suppl.e13068

6. Schrier RW, Sharma S, Shchekochikhin D, Schrier RW, Sharma S, Shchekochikhin D. Hyponatraemia: more than just a marker of disease severity? Nat. Rev. Nephrol. 2012;9:37-50 [cited 2017 Mar 2] Available from: http://www.nature.com/doifinder/10.1038/nrneph.2012.246.

7. Torre LA, Bray F, Siegel RL, Ferlay J, Lortet-Tieulent J, Jemal A. Global cancer statistics, 2012. Cancer J Clin. 2015;65:87-108 [cited 2016 Oct 6] Available from: http://www.ncbi.nlm.nih.gov/pubmed/25651787.

8. Shindel A. AB001.Prostate cancer 2017 update. Transl Androl Urol. 2017:6: AB001-1 [cited 2017 Nov 12] Available from: http://tau.amegroups.com/ article/view/15890/16042.

9. Socialstyrelsen .Available from: http://www.socialstyrelsen.se/.

10. Statistics Sweden | SCB. Available from: http://www.scb.se/en_/\#

11. Walldius $G$, Malmström $H$, Jungner I, de Faire $U$, Lambe $M$, Van Hemelrijck M, et al. The AMORIS cohort. Int J Epidemiol. 2017;47:2033-41 [cited 2017 Feb 13] Available from: http://www.ncbi.nlm.nih.gov/pubmed/28158674.

12. Van Hemelrijck M, Wigertz A, Sandin F, Garmo H, Hellström K, Fransson $P$, et al. Cohort profile: The national prostate cancer register of sweden and prostate cancer data base Sweden 2.0. Int J Epidemiol. 2013;42: 956-67 [cited 2017 Dec 18] Available from: http://www.ncbi.nlm.nih. gov/pubmed/22561842.

13. Samverkan. [cited 2017 Dec 18] Available from: https://www.cancercentrum. se/samverkan/

14. Kastner C, Armitage J, Kimble A, Rawal J, Carter PG, Venn S. The Charlson comorbidity score: A superior comorbidity assessment tool for the prostate cancer multidisciplinary meeting. Prostate Cancer Prostatic Dis. 2006;9:270-4 [cited 2017 Dec 18] Available from: http://www.ncbi. nlm.nih.gov/pubmed/16770340.

15. msdmanuals.com. Blood Tests: Normal Values - Appendixes - MSD Manual Professional Edition. 2015 [cited 2017 Aug 5] Available from: http://www. msdmanuals.com/en-gb/professional/appendixes/normal-laboratory-values/ blood-tests-normal-values\#v8508814
16. International Classification of Diseases, Revision 7 (1955). [cited 2017 Feb 10] Available from: http://www.wolfbane.com/icd/icd7h.htm

17. Arthur R, Williams R, Garmo H, Holmberg L, Stattin P, Malmström H, et al. Serum inflammatory markers in relation to prostate cancer severity and death in the Swedish AMORIS study. Int I Cancer. 2018;142:2254-62 [cited 2018 Sep 30] Available from: http://doi.wiley.com/10.1002/ijc.31256.

18. Ghoshal A, Garmo H, Arthur R, Hammar N, Jungner I, Malmström H, et al. Serum biomarkers to predict risk of testicular and penile cancer in AMORIS. Ecancermedicalscience. Cancer Intelligence. 2017;11:762 [cited 2018 Sep 30] Available from: http://www.ncbi.nlm.nih.gov/pubmed/28900475.

19. Statistical Analysis Software, SAS/STAT | SAS UK. [cited 2016 Dec 31] Available from: http://www.sas.com/en_gb/software/analytics/stat.html

20. Lin DY, Wei L, Ying Z. Checking the Cox model with cumulative sums of martingale-based residuals. Biometrika. 1993;80:557-72 [cited 2018 Sep 30] Available from: https://www.jstor.org/stable/2337177? origin=crossref.

21. Costello LC, Franklin RB. Prostatic fluid electrolyte composition for the screening of prostate cancer: a potential solution to a major problem. Prostate Cancer Prostatic Dis. 2008;12:17. [cited 2017 Dec 10] Available from: http://www.nature.com/doifinder/10.1038/pcan.2008.19.

22. Jeppesen AN, Jensen HK, Donskov F, Marcussen N, von der Maase $H$. Hyponatremia as a prognostic and predictive factor in metastatic renal cell carcinoma. Br J Cancer. 2010;102:867-72 [cited 2017 Aug 1] Available from: http://www.ncbi.nlm.nih.gov/pubmed/20145619.

23. Berardi R, Caramanti M, Fiordoliva I, Morgese F, Savini A, Rinaldi S, et al. Hyponatraemia is a predictor of clinical outcome for malignant pleural mesothelioma. Support. Care Cancer. 2015;23:621-6 [cited 2017 Aug 5] Available: fromhttp://www.ncbi.nlm.nih.gov/pubmed/25142706.

24. Hansen $\mathrm{O}$, Sørensen $\mathrm{P}$, Hansen $\mathrm{KH}$. The occurrence of hyponatremia in SCLC and the influence on prognosis. A retrospective study of 453 patients treated in a single institution in a 10-year period. Lung Cancer. 2010;68:111-4 [cited 2017 Aug 8] Available from: http://www.ncbi.nlm. nih.gov/pubmed/19535164.

25. Çınar $M$, Engin $M$, Engin EZ, Ziya Ateşçi Y. Early prostate cancer diagnosis by using artificial neural networks and support vector machines. Expert Syst Appl. 2009;36:6357-61 [cited 2017 Dec 10] Available from: http://linkinghub. elsevier.com/retrieve/pii/S0957417408005563.

26. Gilbert R, Metcalfe C, Fraser WD, Donovan J, Hamdy F, Neal DE, et al. Associations of circulating 25 -hydroxyvitamin $\mathrm{D}$ with prostate cancer diagnosis, stage and grade. Int J Cancer. 2012;131:1187-96 [cited 2017 Dec 10] Available from: http://doi.wiley.com/10.1002/ijc.27327.

27. Margel D, Urbach DR, Lipscombe LL, Bell CM, Kulkarni G, Austin PC, et al. Metformin use and all-cause and prostate cancer-specific mortality among men with diabetes. J Clin Oncol. 2013;31:3069-75 [cited 2017 Dec 10] Available from: http://ascopubs.org/doi/10.1200/JCO.2012.46.7043.

28. Albanes D, Mondul AM, Yu K, Parisi D, Horst RL, Virtamo J, et al. Serum 25-hydroxy vitamin D and prostate cancer risk in a large nested case-control study. Cancer Epidemiol. Biomarkers Prev. 2011;20: 1850-60 [cited 2017 Dec 10] Available from: http://www.ncbi.nlm.nih. gov/pubmed/21784952.

29. Sfanos KS, Yegnasubramanian S, Nelson WG, De Marzo AM. The inflammatory microenvironment and microbiome in prostate cancer development. Nat Rev Urol. 2017;15:11. [cited 2017 Dec 10] Available from: http://www.nature.com/doifinder/10.1038/nrurol.2017.167

\section{Ready to submit your research? Choose BMC and benefit from:}

- fast, convenient online submission

- thorough peer review by experienced researchers in your field

- rapid publication on acceptance

- support for research data, including large and complex data types

- gold Open Access which fosters wider collaboration and increased citations

- maximum visibility for your research: over $100 \mathrm{M}$ website views per year

At BMC, research is always in progress.

Learn more biomedcentral.com/submission 